\title{
Numerical analysis of the embedded track structure under mixed traffic load
}

Jianqing $\mathrm{Bu}$, and Junpeng $\mathrm{Li}^{*}$

School of Traffic and Transportation, Shijiazhuang Railway University, Shijiazhuang Hebei 050011

China

\begin{abstract}
Taking into account that the embedded track structure not only bears the load from tram, but also suffers from road traffic, this paper aims to establish the finite element analysis model of embedded track structure in the mixed traffic area with ABAQUS software, calculates the deformation and stress of asphalt surface course and filling material. Also, the paper puts forward the way to improve the structural stability of embedded track.
\end{abstract}

\section{Introduction}

As we all know, the embedded track of modern trams is a new type of vibration-damping and noise-reducing track structure[1], the connection between the rail and the track bed is different from the discrete fastening system in the traditional track structure. In detail, it is to set a groove in the asphalt pavement, the rail is placed in the groove, and the polymer filling material is laid under the rail head to fix the rail[2]. This continuous longitudinal support mode greatly reduces the vibration of the track structure, which caused by the irregularity of the conventional discrete support. In addition, the rail is embedded in the road surface does not affect the passage of urban motor vehicles[3, 4]. It can be said this type of tracks is suitable for urban trams, and it is quite adaptive for urban rail transit.

As for the embedded track structure without fastening system, the selection of elastic modulus of filling material is crucial for the design of track structure, because the rail is mainly fixed by the filling material[5]. Therefore, the main purpose of this paper is to study the elastic modulus of the filling material. The method we propose is to establish a finite element model of the embedded track in the mixed traffic area[6, 7], and analyze the local force and deformation law of the track structure under the mixed traffic load and tram load. Hence, we put forward an optimum range of elastic modulus to improving the stability of embedded rail track.

\section{Establish the finite element model}

\subsection{Simplification of track structure}

\footnotetext{
* Corresponding author: ljpjunpengli@163.com
} 
The embedded track is symmetrical along the center line[8], so the track is divided along the longitudinal symmetry center plane, and the $1 / 2$ track structure is taken as the calculation model[5]. The track structure is shown in figure 1.

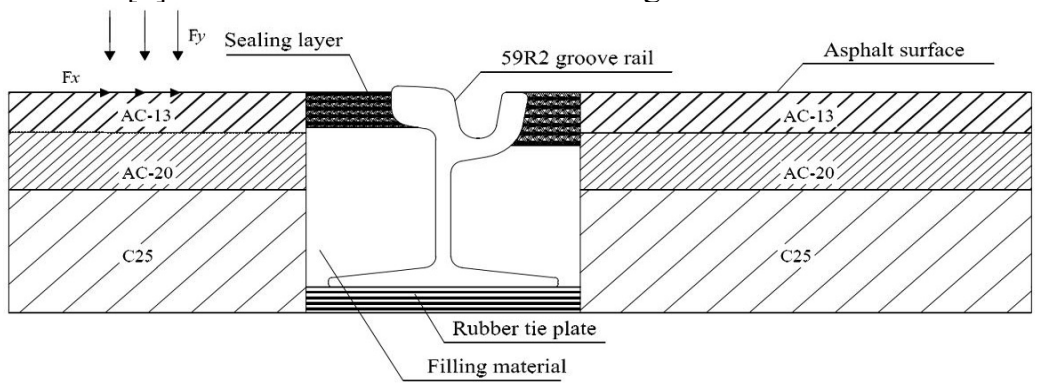

Fig. 1. transverse section of embedded track.

The material parameters of each component of embedded track structure are shown in table 1 .

Table 1. Parameters of the embedded track structure.

\begin{tabular}{|c|c|c|}
\hline Parameters & Elastic modulus, $E / \mathrm{MPa}$ & Poisson's ratio, $\mu$ \\
\hline 59R2 Groove rail & $2.06 \times 10^{5}$ & 0.30 \\
\hline Rubber tie plate & 7.8 & 0.47 \\
\hline Filling material & 16 & 0.40 \\
\hline AC-13 & $1.4 \times 10^{3}$ & 0.35 \\
\hline AC-20 & $1.2 \times 10^{3}$ & 0.30 \\
\hline C25 & $2.8 \times 10^{4}$ & 0.20 \\
\hline
\end{tabular}

As is shown in figures $2-3$, the model is divided into 86273 three-dimensional hexahedral entity elements with ABAQUS. The detailed values of the given parameters are listed in table 2.

Table 2. Parameters of the model(m).

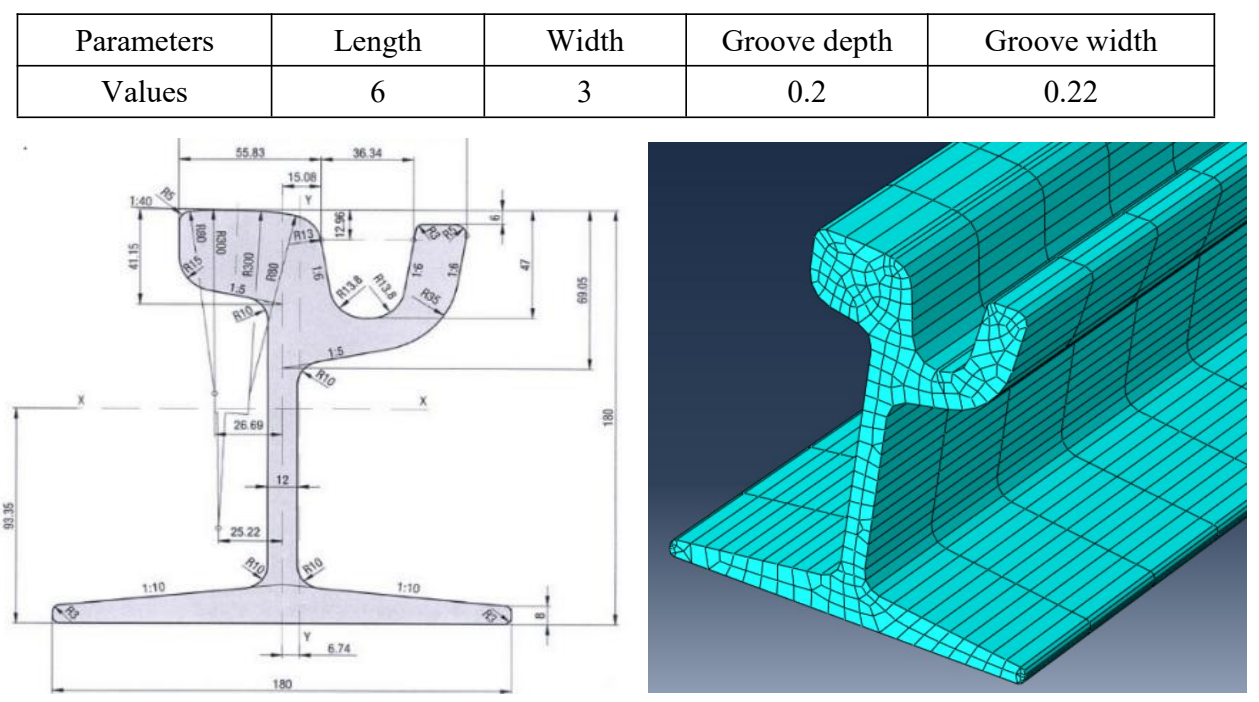

Fig. 2. Finite element model of 59R2 Groove rail. 


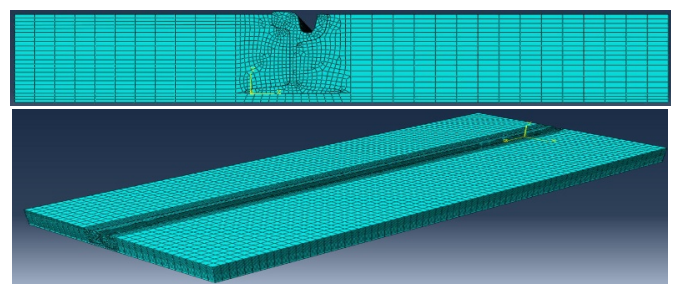

Fig. 3. Schematic display of the FE-model.

\subsection{Load and working conditions}

Based on references[5, 7, 9, 10], under the mixed traffic area, the vehicle crosses the embedded track structure, the vehicle load is set separately on the outside of the rail and the inside of the rail. The loading area of the wheel is $0.6 \mathrm{~m} \times 0.2 \mathrm{~m}[11]$. Considering the most disadvantageous condition, the wheel load acts on the rail, and the working area of the wheel load is $0.03 \mathrm{~m} \times 0.2 \mathrm{~m}$. Therefore, there are five kinds of vehicle loading conditions. The setting conditions are as follows:

Operating condition 1, the vehicle loads acts on the outer side of the rail, the working area of the wheel load is $0.6 \mathrm{~m} \times 0.2 \mathrm{~m}$, the wheel distance is $1.8 \mathrm{~m}$, the vertical force is $140 \mathrm{kN}$, the horizontal force is oriented to the inner side of the rail, and the value is $84 \mathrm{kN}$;

Operating condition 2, the vehicle load acts on the inner side of the rail, the area of the wheel load action, wheel distance, vertical force and horizontal force are the same as the operating condition 1, and the horizontal force is oriented to the outside of the rail;

Operating condition 3 , the vehicle load acts on the rail, the working area of wheel load is $0.03 \mathrm{~m} \times 0.2 \mathrm{~m}$, the wheel distance is $1.8 \mathrm{~m}$, the vertical force is $140 \mathrm{kN}$, the horizontal force is oriented to the inner side of the rail, and the value is $84 \mathrm{kN}$;

Operating condition 4, the vehicle load acts on the rail, the area of the wheel load action, wheel distance, vertical force and horizontal force are the same as the operating condition 3 , the horizontal force is oriented to the outer side of the rail;

Operating condition 5, the tram load acts on the center of the surface of the rail, the vertical force is $170 \mathrm{kN}$, and the horizontal force is $102 \mathrm{kN}$, which is 0.6 times the vertical force.

\section{Results and discussions}

The influence of elastic modulus change of filling material on tensile stress and compressive stress of asphalt layer are shown in figure 4 and figure 5 , and the influence on its own tensile stress and compressive stress are shown in figure 6 and figure 7 . The influence of elastic modulus of filling material on the deformation of asphalt layer is shown in figure 8 and figure 9. Figure 10 and figure 11 show the influence of elastic modulus variation on the deformation of filling materials. Figure 12 and figure 13 show the variation of rail displacement under the different elastic modulus of filling materials. 


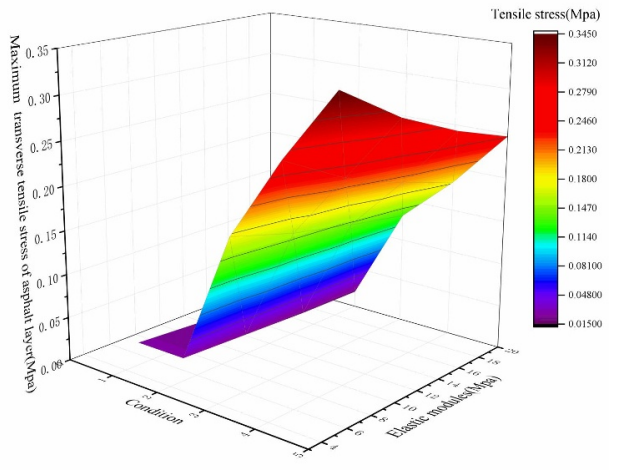

Fig. 4. Transverse tensile stress of asphalt layer under different elastic modulus of filling material.

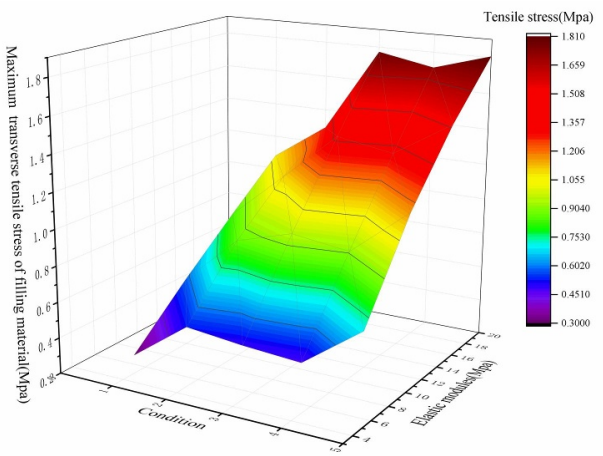

Fig. 6. Transverse tensile stress of filling material under different elastic modulus of filling material.

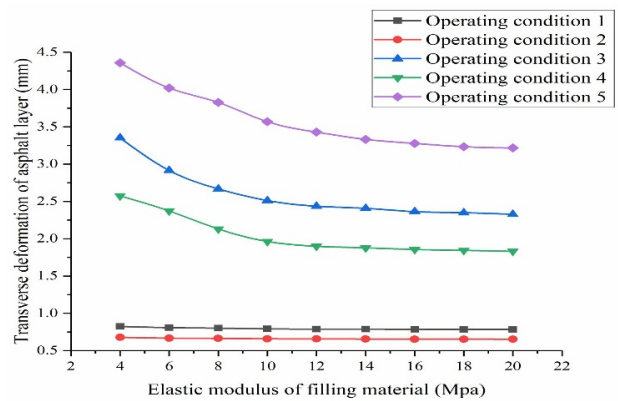

Fig. 8. Effect of elastic modulus of filling material on transverse deformation of asphalt layer.

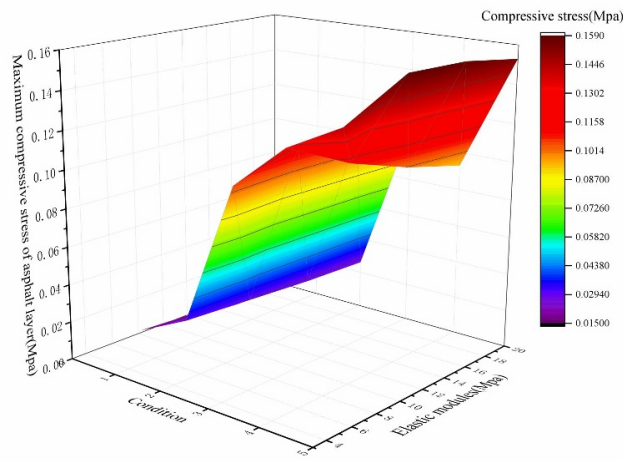

Fig. 5. compressive stress of asphalt layer under different elastic modulus of filling material.

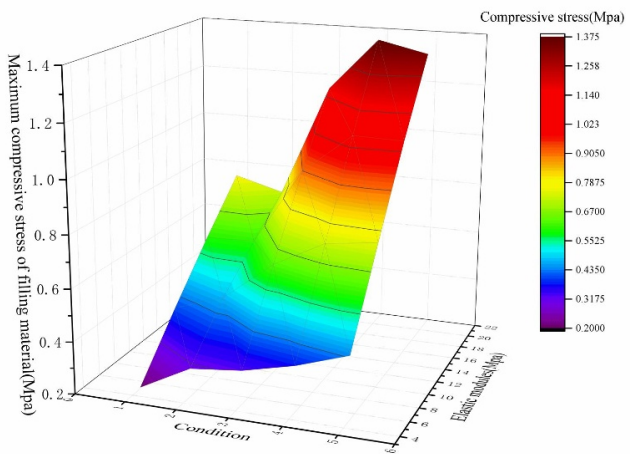

Fig. 7. compressive stress of filling material under different elastic modulus of filling material.

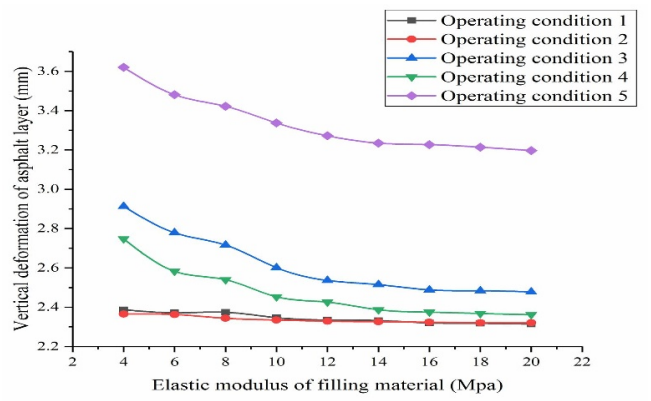

Fig. 9. Effect of elastic modulus of filling material on vertical deformation of asphalt layer. 


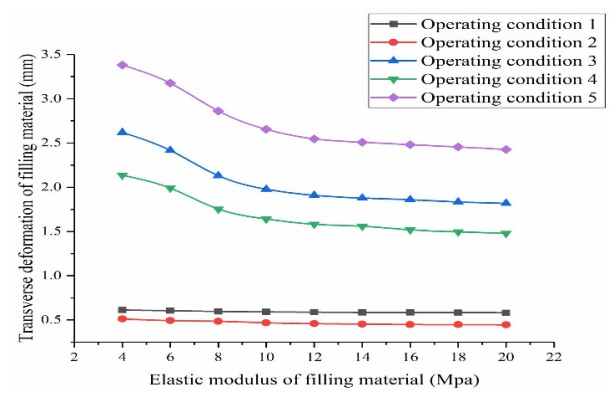

Fig. 10. Effect of elastic modulus of filling material on transverse deformation of filling material.

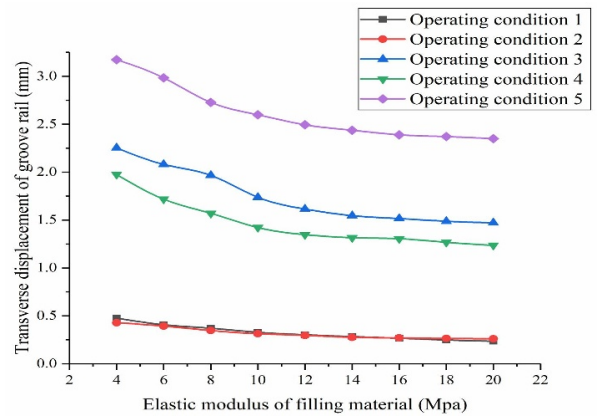

Fig. 12. Effect of elastic modulus of filling material on transverse displacement of groove rail.

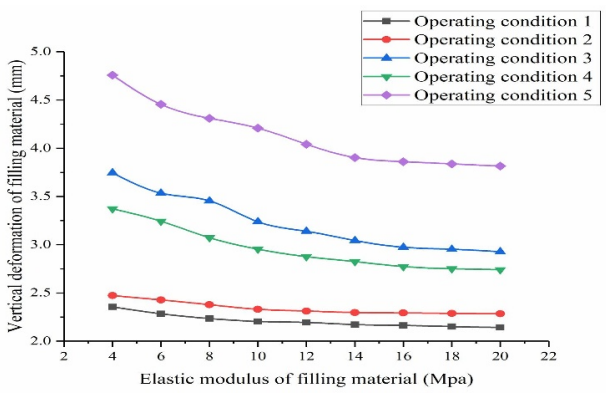

Fig. 11. Effect of elastic modulus of filling material on vertical deformation of filling material.

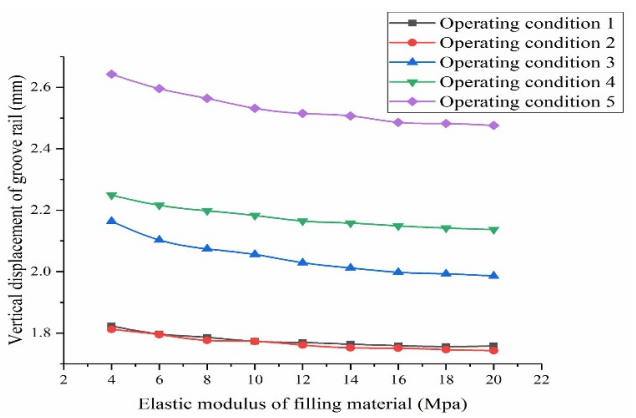

Fig. 13. Effect of elastic modulus of filling material on vertical displacement of groove rail.

\subsection{Deformation and stress law of asphalt layer}

When tram load (operating condition 5) or vehicle load (operating condition 3 and 4) acts on the rail, as shown in Figure 8, with the increase of elastic modulus of filling materials, the transverse deformation of asphalt layer is decreasing. When the elastic modulus is in the range of $4-12 \mathrm{Mpa}$, the decreasing rate is obvious, and when the modulus is more than $16 \mathrm{MPa}$, the decreasing rate tends to gentle. When the elastic modulus of filling material is $4 \mathrm{MPa}$, the maximum transverse displacement of asphalt layer under tram load is $4.357 \mathrm{~mm}$, and $3.352 \mathrm{~mm}$ under vehicle load, the difference of both is 25 percent. When the vehicle load acts on both sides of the rail (operating conditions 1 and 2), the vehicle load has little influence on the transverse deformation of the asphalt layer.

It can be seen from Figure 9, compared with the transverse deformation of asphalt layer, vertical deformation also presented the same trend. When the elastic modulus of filling material is the same, the vertical deformation of asphalt layer under the tram load (operating condition 5) is much larger than other operating conditions. When the elastic modulus of the filling material is $4 \mathrm{MPa}$, the maximum value of $3.624 \mathrm{~mm}$ is obtained. When the vehicle load (operating conditions 1 and 2) acts on both sides of the track structure, the vertical deformation of asphalt layer is basically the same, and it basically does not change with the change of the elastic modulus of the filling material.

It can be seen from Figures 4-5, compared with the five operating conditions, under the action of tram load, the asphalt layer will bear greater tensile and compressive stress, and will decrease linearly with the increase of elastic modulus of the filling material. Due to the asymmetry of groove rail structure, the maximum tensile stress of asphalt layer is about $50 \%$ more when the vehicle load acts on the rail outwards than inwards. When the vehicle 
load acts on both sides of the rail, the tensile stress of asphalt is much smaller than other operating conditions.

\subsection{Deformation and stress law of filling material}

Figures 10-11 show the maximum transverse and vertical deformation of the filling material under different operating conditions. The deformation of the filling material is substantially the same as the asphalt layer. When the vehicle load (operating conditions 1 and 2) acts on both sides of the track structure, the transverse and vertical deformation of filling material is basically the same, and it does not change with the change of the elastic modulus of the filling material. when tram load (operating condition 5) or vehicle load (operating condition 3 and 4) acts on the rail, the transverse and vertical deformation of filling material decreases with the increase of elastic modulus of filling materials. When the elastic modulus is in the range of $4-14 \mathrm{MPa}$, the decreasing rate is obvious, and when the modulus is larger than $16 \mathrm{MPa}$, the decreasing rate tends to gentle.

It can be seen from figure 7 , under different operating conditions, the maximum variation law of the compressive stress of filling material is not obvious. When the elastic modulus of the filling material is the same, the maximum compressive stress of the filling material under tram load is greater than that under other conditions, but its change law does not change linearly with the increase of elastic modulus of filling materials. When the elastic modulus of filling material is $12 \mathrm{MPa}$, the compressive stress of filling material reaches the maximum value of $0.159 \mathrm{MPa}$. The maximum compressive stress of filling material decreases linearly when the vehicle load acts on the rail (operating condition 3). When the vehicle load acts on both sides of the track, the compressive stress is much smaller than other operating conditions.

It is not difficult to find that the tensile stress increases with the increase of elastic modulus of the filling materials, as shown in figure 6 . In operating condition 3,4 and 5, the elastic modulus of the filling material is small $(4-12 \mathrm{MPa})$, and the tensile stress increases greatly with the increase of the elastic modulus of the filling material. The above data show that the maximum tensile stress of the filling material increases rapidly with the increase of the elastic modulus of the filling materials. In order to control the linear increase of the tensile and compressive stress of the filling materials, larger elastic modulus cannot be selected.

\subsection{Displacement law of groove rail}

It can be seen from Figures 12-13, compared with the five operating conditions, the transverse displacement of the groove rail decreases with the increase of elastic modulus of filling materials. When the vehicle load acts on both sides of the rail (operating conditions 1 and 2), the vehicle load has little influence on the transverse displacement of the groove rail. The vertical displacement is basically in the same trend. The maximum vertical displacement of groove rail under tram load is $2.643 \mathrm{~mm}$, and the minimum vertical displacement of groove rail is $2.476 \mathrm{~mm}$, appearing a 7 percent gap. It shows that the elastic modulus of the filling material has no obvious influence on the vertical displacement of groove rail.

\section{Concluding remarks}

In this paper, the calculation model of embedded track structure in the mixed traffic area is established. By analysing the mechanical properties of each part of the track, the structural parameters of the embedded track without fastener are optimized. The main conclusions are as follows: 
Under the same operating condition, the change of elastic modulus of the filling material has great influence on its transverse and vertical deformation, which generally shows that the deformation decreases with the increase of the elastic modulus, especially when the load acts on the rail. However, with the increase of elastic modulus, the rate of deformation reduction also tends to gentle.

Because the elastic modulus of asphalt concrete on both sides of the track structure is much larger than the elastic modulus of the filling material, the vehicle load has little influence on the vertical displacement of groove rail.

Considering the mechanical properties of asphalt layer and filling material under five operating conditions, whether it is deformation of asphalt layer or filling material, the displacement of the groove rail, it basically decrease as the elastic modulus of filling material increases. When the elastic modulus of the filling material is small, the transverse and vertical deformation is relatively large and the reduction rate is obvious. When the elastic modulus is greater than $16 \mathrm{MPa}$, the reduction rate tends to gentle. At the same time, in order to control the linear increase of the tensile and compressive stress of the filling material, the larger elastic modulus of the filling material cannot be selected. In order to improve the stability of track structure, it is suggested that $14-16 \mathrm{MPa}$ is more suitable.

\section{References}

1. Yang J, Song H, Fu L, Wang M, Li W. A new solution method for wheel/rail rolling contact. SPRINGERPLUS. 2016; 5:471.

2. Zou JXXJ, Guangdong UOT, Guangzhou. ANALYSIS OF DYNAMIC RESPONSE OF AN EMBEDDED RAILWAY TRACK SUBJECTED TO A MOVING LOAD. Vibration Engineering and Technology of Machinery2009. p. 1.

3. Cheng HM, Ning YZ, Ma X, Liu X, Zhang ZY. Effectiveness of rapid rail transit system in Beijing. PLOS ONE. 2017; 12:e180075.

4. Huang R, Moudon AV, Zhou C, Stewart OT, Saelens BE. Light Rail Leads to More Walking Around Station Areas. J Transp Health. 2017; 6:201-8.

5. Kalliainen A, Kolisoja P, Nurmikolu A. 3D Finite Element Model as a Tool for Analyzing the Structural Behavior of a Railway Track. Procedia Engineering. 2016; 143:820-7.

6. Fangyao Y, Xiaoting C, Yuchi S. Numerical and Experimental Study on Vibration and Noise of Embedded Rail System. Suzhou, Jiangsu, China2017. p. 9.

7. Shih JY, Thompson DJ, Zervos A. The effect of boundary conditions, model size and damping models in the finite element modelling of a moving load on a track/ground system. SOIL DYN EARTHQ ENG. 2016; 89:12-27.

8. Nishiura D, Sakaguchi H, Aikawa A. Development of Viscoelastic Multi-Body Simulation and Impact Response Analysis of a Ballasted Railway Track under Cyclic Loading. Materials (Basel). 2017; 10.

9. Lou P. A vehicle-track-bridge interaction element considering vehicle's pitching effect. FINITE ELEM ANAL DES. 2005; 41:397-427.

10. Lou P. Finite element analysis for train-track-bridge interaction system. ARCH APPL MECH. 2007; 77:707-28.

11. Montalban DL, Zamorano MC, Palenzuela AC, Real HJ. Analysis of the influence of cracked sleepers under static loading on ballasted railway tracks. ScientificWorldJournal. 2014; 2014:363547. 